\title{
Derges's designs
}

Drop sheets of photographic paper into a river and let the play of light and water paint its own picture. That is one of the innovative techniques used by Susan Derges in her 'photo-works'.

\section{Martin Kemp}

$\mathrm{N}$ ature is an alarmingly tough competitor for any artist. It parades an endless succession of beguiling and elusive effects whose subtlety and vitality present an enduring challenge to the inert media available to the painter and sculptor.

In particular, the capturing of the transitory beauties of light and motion in water has presented perpetual problems, to be faced by the Renaissance painter of the Baptism of Christ or Birth of Venus no less than by an Impressionist seeking to evoke a seascape saturated with sunlight and fractured by scattered reflections of rocks and trees.

One solution to the problem of entrapping such natural effects is brilliantly realized by the Devon artist, Susan Derges. She collaborates directly with the natural phenomena themselves, in such a way that nature inscribes its own order and disorder on the designated surfaces of the works of art.

Derges is internationally admired for her photo-works in which nature imprints patterns and rhythms of motion, growth and form directly on the light-sensitive surface of the photographic emulsion. She has collaborated intensively with such phenomena as falling water drops, busy honeycombs and vessels of germinating toad's eggs. Such images make us look again - look really hard - in keeping with a historical succession that runs through Leonardo, Dürer, Goethe and Ruskin. Her most recent work tackles the motion of water, that hell of the predictive sciences.

In one series she is treating the surface of a river, the Taw in Devon, as a photographic transparency, searching out flow patterns that remain relatively stable. Sheets of photographic paper in a large slide (about 6 feet by 2 feet) are immersed just below the surface at night and illuminated by a brilliant but diffuse flash lasting a microsecond. The colour images register the peaks of the wavelets as whitelines and the troughs as tinted by moonlight and reflected vegetation. The black-andwhite photographs, such as the one illustrated here, are made with a negative process which inverts the tonality. The crests accordingly are represented as a rippling cellular network of dark membraneous filaments.

In a technical sense, a student of hydraulics might scrutinize her large prints as lucid illustrations of wave trains, capillary waves and so on. But they are more than technical illustrations. They suggestively
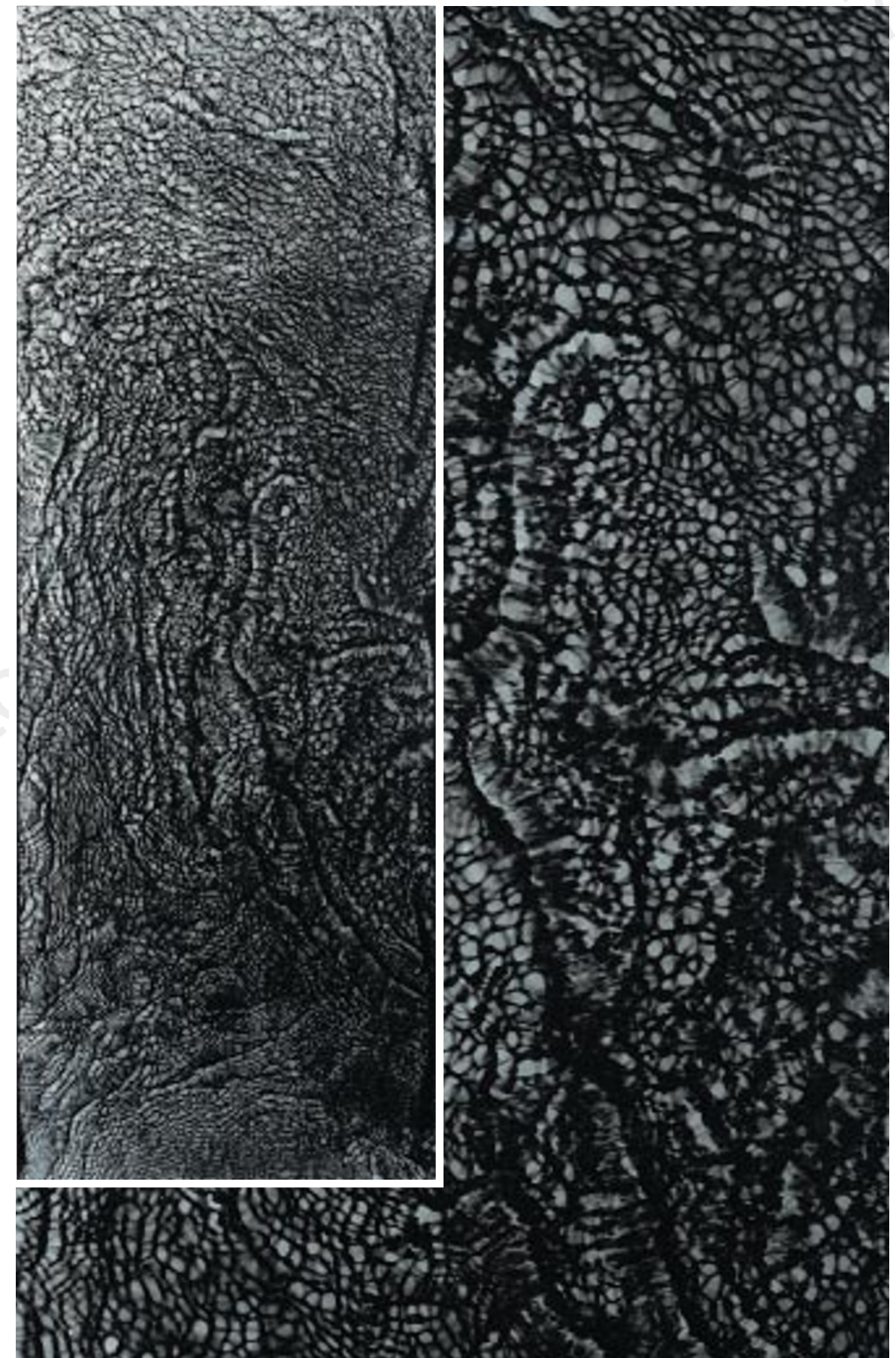

Susan Derges's Untitled Photogram (Riusr Tor, 1966) (inset) and detail (main picture).

evoke the pattern-forming propensities of physically diverse phenomena, not only those exhibited dynamically by fluids but also those discernible in the growth of cells, the wrinkling of tissues and so on - across a wide range of scales.

At one level, the images are life-size representations of very specific events. And they are unusually large for photographs. Yet, at another level, these and others of her works aspire to reveal scale-less commonalities in nature, both as sensed intuitively and as investigated mathematically within chaos theory.

Martin Kemp is in the Department of the History of Art, University of Oxford, 35 Beaumont Street, Oxford OX1 2PG, UK 